

Edukatif : Jurnal Ilmu Pendidikan Volume 3 Nomor 5 Tahun 2021 Halm 2419 - 2429

EDUKATIF: JURNAL ILMU PENDIDIKAN

Research \& Learning in Education

https://edukatif.org/index.php/edukatif/index

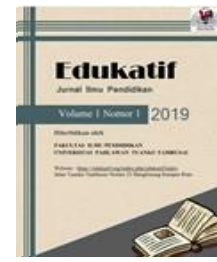

\title{
Model Pembelajaran Guided Discovery Learning, Apakah Efektif dalam Meningkatkan Kemampuan Berfikir Kritis Siswa?
}

\author{
Amanda Pasca Rini' ${ }^{1 凶}$, I'in Khalimatus Sa'diyah², Abdul Muhid ${ }^{3}$ \\ Universitas 17 Agustus 1945 Surabaya, Indonesia ${ }^{1,2}$ \\ UIN Sunan Ampel Surabaya, Indonesia ${ }^{3}$ \\ E-mail : $\underline{\text { amanda@ untag-sby.ac.id }}^{1}, \underline{\text { isadiyah_s2@untag-sby.ac.id }}^{2}, \underline{\text { abdulmuhid@uinsby.ac.id }}^{3}$
}

\begin{abstract}
Abstrak
Kemampuan berfikir kritis sebagai salah satu keterampilan yang harus dimiliki siswa di abad-21. Dengan memiliki kemampuan berfikir kritis diharapkan siswa mampu meraih sukses dalam kehidupannya. Kemampuan ini bisa diperoleh atau ditingkatkan melalui model pembelajaran tertentu, seperti guided discovery learning. Model pembelajaran kontruktivisme ini akan melatih siswa terlibat aktif serta mengakomodasi kemampuan berpikir kritis mereka. Tujuan Penelitian adalah untuk mengetahui efektivitas penggunaan model pembelajaran guided discovery learning dalam meningkatkan kemampuan berfikir kritis siswa. Metode penelitian yang digunakan adalah literature review atau studi kepustakaan dengan menggunakan penelusuran pustaka seperti buku-buku dan artikel secara online maupun cetak, melalui database seperti Researchgate, Spencer Journal dan google scholar. Berdasarkan artikel yang dikumpulkan diperoleh bahwa model pembelajaran guided discovery learning dapat meningkatkan kemampuan berfikir kritis siswa. Melalui topik utama yang disampaikan guru, siswa akan menyusun hipotesis berdasarkan pengetahuan awal yang mereka dapatkan, kemudian siswa bisa mulai bereksperimen, hingga dapat disimpulkan sebuah konsep atas pengetahuan tertentu.
\end{abstract}

Kata Kunci: Berfikir Kritis, Guided Discovery Learning, Abad-21.

\section{Abstract}

The ability to think critically is one of the skills that must be possessed by students in the 21st century. By having the ability to think critically, students are expected to be able to achieve success in life. This ability can be obtained or enhanced through certain learning models, such as guided discovery learning. This constructivism learning model will train students to be actively involved and accommodate their critical thinking skills. The purpose of the study is to determine the effectiveness. The research method used is a literature review or literature study using library searches such as books and articles online and in print, through databases such as Researchgate, Spencer Journal and Google Scholar. Based on the articles collected, it was found that the guided discovery learning model could improve students' critical thinking skills. Through the main topics presented by the teacher, students will formulate hypotheses based on the initial knowledge they get, then students can start experimenting, so that a concept can be concluded on certain knowledge.

Keywords: Critical Thinking, Guided Discovery Learning, 21st Century

Copyright (c) 2021 Amanda Pasca Rini, I'in Khalimatus Sa'diyah, Abdul Muhid

$\triangle$ Corresponding author

Email : amanda@untag-sby.ac.id

DOI $\quad$ : https://doi.org/10.31004/edukatif.v3i5.641

ISSN 2656-8063 (Media Cetak)

ISSN 2656-8071 (Media Online)

Edukatif : Jurnal Ilmu Pendidikan Vol 3 No 5 Tahun 2021 p-ISSN 2656-8063 e-ISSN 2656-8071 
2420 Model Pembelajaran Guided Discovery Learning, Apakah Efektif dalam Meningkatkan Kemampuan Berfikir Kritis Siswa? - Amanda Pasca Rini, I'in Khalimatus Sa'diyah, Abdul Muhid

DOI: https://doi.org/10.31004/edukatif.v3i5.641

\section{PENDAHULUAN}

Perkembangan teknologi di era digital sekarang terjadi pada hampir seluruh lini kehidupan yang menjadi tanda dimulainya abad 21. Pada era sekarang, semua dapat terhubung dan saling berbagi informasi dengan orang lain di seluruh dunia tanpa terhalang batas ruang dan waktu. Adanya berbagai perubahan kebiasaan dalam abad 21 menuntut sumber daya manusia memiliki kemampuan dan kompetensi yang memadai. Lebih spesifik lagi pada aspek pendidikan, ada tuntutan baru bagi siswa yang jauh lebih kompleks dibandingkan pada zaman-zaman sebelumnya. Siswa diharapkan belajar lebih giat dan proaktif dalam menjawab tantangan global (Diah Rusmala Dewi, 2019), bukan sekedar mampu menghafal beberapa materi pelajaran namun lebih kompleks daripada itu. Konsep pendidikan yang lebih dikenal dengan long life education menjadi salah satu acuan dari proses pembelajaran, yaitu belajar sepanjang masa dengan mengelola dan memahami informasi yang diperoleh sehingga siswa diharapkan mampu memecahkan masalah dengan baik serta menjadi pemikir yang kreatif dan inovatif (Drake \& Reid, 2018). Selain pengetahuan, pengembangan keterampilan juga dituntut untuk mampu dikuasi siswa seperti kreativitas, berfikir secara kritis, team work, dan beberapa keterampilan lainnya yang memberikan pengaruh secara langsung dalam kehidupan bermasyarakat mereka (Putriani, 2021).

Berbagai kemampuan atau keterampilan menjadi modal utama yang harus dikuasai siswa dalam menyikapi pelbagai perubahan pada abad 21 yang termuat dalam P21 Framework for 21st Century Learning, Kerangka ini terus digunakan oleh ribuan pendidik dan ratusan sekolah di AS dan luar negeri untuk digunakan di pusat pembelajaran (Partnership for 21st Century - A Network of Battelle for Kids [P21], 2019). Setiap implementasi keterampilan abad ke-21 membutuhkan pengembangan pengetahuan akademis di antara semua siswa. Diantara kemampuan yang harus dimiliki siswa antara lain berfikir kritis dan mampu berkomunikasi dengan orang lain secara efektif harus berlandaskan pengetahuan akademis. Membahas tentang dunia pendidikan, penting sekali siswa diharapkan menguasai keterampilan atau kemampuan tertentu sesuai bidang yang diminati agar sukses di kehidupannya, seperti kemampuan berfikir kritis, problem solving (pemecahan masalah), komunikatif, dan kolaborasi (Battele for kids, 2019). Sejalan dengan pendapat di atas bahwa terdapat beberapa hal yang mempengaruhi keberhasilan individu dalam kehidupan mereka salah satunya adalah kreativitas individu tersebut. Diantara ciri-ciri yang dimiliki individu kreatif adalah berimajnatif dan berfikir secara kritis (Collard \& Looney, 2014). Konsep berfikir kritis berlaku untuk semua bidang pengetahuan yang menjelaskan keterlibatan siswa dalam membangun sebuah pengetahuan melalui proses berfikir secara mendalam. Keingintahuan yang diwujudkan dalam banyak pertanyaan merupakan karakteristik dalam berfikir kritis karena siswa akan berusaha mendapatkan jawaban atas keingintahuan mereka (Saleh, 2019).

Setiap manusia memiliki permasalahan-permasalahan yang harus dihadapi, begitupun dengan siswa. Pada proses pembelajaran mereka akan menjumpai berbagai masalah baik yang berkaitan dengan materi pembelajaran atau masalah pribadi masing-masing. Untuk menyikapi keadaan tersebut hendaknya siswa dibekali informasi atau pengalaman belajar yang melibatkan kemampuan berfikir kritis mereka. Dalam menentukan solusi atas permasalahan yang mereka hadapi tentu dibutuhkan proses yang tidak sederhana seperti berfikir secara kritis, agar apabila ditemukan keterangan atau informasi yang belum pasti kebenarannya hendaknya tidak dipercaya begitu saja (Purwanto et al., 2012). Di sinilah landasan pemikiran pentingnya kemampuan berfikir secara kritis perlu diajarkan dan dikembangkan baik secara akademik maupun non akademik. Terdapat beberapa hal yang menjadi factor pendukung atau melemahkan kemampuan berfikir kritis siswa yaitu model pembelajaran yang dipilih guru dalam proses belajar mengajar di kelas (Haris et al., 2015). Oleh karenanya penentuan model pembelajaran harus berdasarkan banyak pertimbangan seperti kesesuaian model dengan materi yang disampaikan, dan pemahaman secara mendalam karakteristik masing-masing siswa, sehingga dalam pross belajar mengajar siswa bukan saja menjadi objek pembelajaran tetapi mereka 
2421 Model Pembelajaran Guided Discovery Learning, Apakah Efektif dalam Meningkatkan Kemampuan Berfikir Kritis Siswa? - Amanda Pasca Rini, I'in Khalimatus Sa'diyah, Abdul Muhid

DOI: https://doi.org/10.31004/edukatif.v3i5.641

merupakan subjek yang secara aktif menerima informasi-informasi baru dan menanyakan kembali jika terdapat hal yang kurang dimengerti sampai terbentuk konsep yang sebenarnya (Mukarromah, 2018).

Santrock berpendapat tentang berfikir kritis bahwa "critical thinking involves thinking reflectively, productively and evaluating evidence" (Santrock J.W., 2011). Berdasarkan argumen di atas dapat disimpulkan bahwa dengan berfikir kritis akan diperoleh hasil yang memuaskan serta manfaat tertentu karena siswa akan melakukan evaluasi secara mendalam atas informasi yang mereka terima, tidak sekedar menerimanya begitu saja. Beberapa model tertentu memberikan sumbangsih dalam pencapaian hasil belajar, dalam hal ini pendekatan pembelajaran berbasis masalah mampu meningkatkan kemampuan berfikir kritis siswa (Fachrurazi, 2011) dengan model Guided Discovery Learning (Purwanto et al., 2012). Menurut Kurniasih \& Sani Discovery learning adalah proses pembelajaran yang dalam penyajiannya tidak ditampilkan secara utuh, melainkan hanya sebagian saja dengan harapan siswa dapat menkontruksikannya sendiri (Salmi, 2019).

Metode Guided Discovery Learning dikembangkan oleh J. Bruner yang berawal dari teori discovery menyatakan bahwa hal utama dari proses belajar adalah individu mampu memilih informasi yang diterima kemudian mentransformasikan kembali informasi tersebut secara aktif (Dahar, 2011). Senada dengan pendapat di atas bahwa model pembelajaran yang menggunakan pendekatan teori discovery merupakan salah satu model yang mengutamakan keaktifan siswa selama proses belajar berlangsung sehingga mereka dapat merumuskan sendiri informasi-informasi yang diperoleh secara ilmiah. Dari penjelasan tersebut dapat disimpulkan bahwa model ini memiliki kelebihan dibandingkan model konvensional lainnya antara lain menjadikan siswa proaktif selama mengikuti pelajaran dengan baik, siswa dapat membangun konsep-konsep baru secara benar, serta selama proses menemukan jawaban atas pertanyaan-pertanyaan yang muncul dapat menimbulkan kepuasan tersendiri karena telah melewati tahapan-tahapan yang detail (Purwanto et al., 2012).

Kontuktivisme sebagai teori utama dari model pembelajaran discovery, yang pada prosesnya guru sebagai fasilitator hanya menyampaikan topik materi kepada siswa, kemudian siswa akan membangun sendiri informasi tersebut melalui percobaan tertentu dengan strategi yang benar beerdasarkan arahan guru (Trianto, 2014). Dalam proses melakukan percobaan dan pencarian jawaban siswa akan dibimbing oleh guru serta saling membantu dengan siswa lainnya (Ahman \& Budiwati, 2018). Secara umum, model guided discovery ini lebih efektif dalam pembelajaran dibandingkan free discovery. Adapun kriteria pencapaian yang akan diperoleh siswa antara lain informasi-informasi yang dibangun siswa akan digunakan dalam membuat pengetahuan bar, dan siswa akan melalukan intepretasi terhadap informasi yang baru saja diterima dengan informasi yang telah dimiliki sebelumnya (Mayer, 2004).

Berdasarkan paparan di atas, model pembelajaran yang akan digunakan oleh guru memiliki perang yang signifikan terhadap keberhasilan siswa. Apalagi dalam menghadapi tuntutan di abad 21 maka siswa harus memiliki kecakapan dalam berbagai aspek diantaranya adalah kemampuan berfikir kritis. Dalam penulisan ini akan dibahas mengenai efektivitas model pembelajaran guided discovery learning dalam upaya meningkatkan kemampuan siswa dalam hal berfikir kritis. Terdapat beberapa penelitian sebelumnya yang membahas topik yang sama dengan penelitian ini, namun ada perbedaan diantara keduanya. Pada penelitian sebelumnya hanya membahas model guided discovery learning yang digunakan untuk materi atau pelajaran tertentu, misalnya Fisika (Hidayat et al., 2016). Sedangkan dalam penelitian ini model tersebut bisa dikondisikan pada semua materi atau pelajaran, mengingat pentingnya kemampuan berfikir kritis yang dapat memberikan dampak positif dalam kehidupan sehari-hari.

\section{METODE PENELITIAN}

Penelitian ini menggunakan metode literature review atau studi kepustakaan, yaitu suatu metode penelitian yang menggunakan penelusuran pustaka seperti buku-buku dan artikel sebagai acuan bahan referensi baik secara online maupun cetak. Literature review adalah sebuah penelusuran kepustakaan dari 
2422 Model Pembelajaran Guided Discovery Learning, Apakah Efektif dalam Meningkatkan Kemampuan Berfikir Kritis Siswa? - Amanda Pasca Rini, I'in Khalimatus Sa'diyah, Abdul Muhid

DOI: https://doi.org/10.31004/edukatif.v3i5.641

berbagai sumber referensi baikbuku maupun artikel dengan topik yang sama sehingga dihasilkan sebuah topik tertentu (Marzali, 2016). Buku dan artikel yang dirujuk melalui database antara lain Researchgate, Sciencedirect dan google schoolar dipilih berdasarkan topik dalam penelitian ini yaitu kemampuan berfikir kritis dan model pembelajaran guided discovery learning.

Seluruh sumber referensi yang digunakan sebagai rujukan dalam literature review berkisar pada rentang tahun 1999 sampai yang terupdate yaitu tahun 2021. Dalam penelusuran artikel digunakan keyword yang berkaitan dengan topik literature review yaitu kemampuan berfikir kritis, critical thinking, Framework for 21st Century Learning, dan guided discovery learning. Berikut adalah beberapa artikel dan buku yang digunakan penulis sebagai acuan dalam penyusunan artikel ini, antara lain :

Tabel.1 Daftar Sumber Referensi

\begin{tabular}{lcc}
\hline \multicolumn{1}{c}{ JUDUL } & PENULIS & SUMBER \\
\hline Metode Guided Discovery Learning terhadap & Ahman, E., \& Budiwati, N. & Google Schoolar \\
Tingkat Berpikir Kritis Siswa Dilihat dari & & \\
Motivasi Belajar. & &
\end{tabular}

\begin{tabular}{ll}
\hline $\begin{array}{l}\text { Model Pembelajaran Guided Discovery (Gd ) } \\
\text { Disertai Media Audiovisual dalam }\end{array}$ & $\begin{array}{l}\text { Ariyani, R. D., Indrawati, \& } \\
\text { Mahardika, I. K. }\end{array}$
\end{tabular}

Pembelajaran Ipa ( Fisika ) di SMP

A Research on Critical Thinking Tendencies and Factors that Affect Critical Thinking of Arslan, R., Gulveren, H., \& Aydin, Google Schoolar Higher Education Students. E.

Perbandingan antara Keefektifan Model Imawan, O. R. Google Schoolar

Guided Discovery Learning dan Project-

Based Learning pada Matakuliah Geometri.

Should There Be a Three-Strikes Rule against $\quad$ Mayer, R. E. Google Schoolar
Pure Discovery Learning? The Case for

\begin{tabular}{lll}
\hline $\begin{array}{l}\text { Learner Centred Approaches In Medical } \\
\text { Education. }\end{array}$ & Spencer, J. A., \& Jordan, R. K. & Google Schoolar \\
\hline Teori-tori Belajar \& Pembelajaran. & Dahar, W.R. (2011) & Buku \\
\hline Strategi dan model pembelajaran. & Eggen, P \& Kauchak, D. (2012) & Buku \\
\hline $\begin{array}{l}\text { Mendesain Model Pembelajaran Inovatif- } \\
\text { Progresif. Jakarta: Kencana Prenada Media }\end{array}$ & Trianto (2014) & Buku \\
Group & & \\
\hline
\end{tabular}

Integrated Curriculum as an Effective Way to Drake, S., \& Reid, J.

ResearchGate

Teach 21st Century Capabilities.

\begin{tabular}{lll}
\hline European Journal Of Foreign Language & Saleh, S. E. & ResearchGate \\
Teaching Critical Thinking As A 21 St & \\
Century Skill: Conceptions, Implementation & \\
And Challenges In The Efl Classroom. & & \\
\hline
\end{tabular}

The effects of argument mapping-infused critical thinking instruction on reflective judgement performance.

Dwyer, C. P., Hogan, M. J., \& ScienceDirect Stewart, I. 
2423 Model Pembelajaran Guided Discovery Learning, Apakah Efektif dalam Meningkatkan Kemampuan Berfikir Kritis Siswa? - Amanda Pasca Rini, I'in Khalimatus Sa'diyah, Abdul Muhid

DOI: https://doi.org/10.31004/edukatif.v3i5.641

\author{
Creative learning environments in education- Davies, D., Jindal-Snape, D., Collier, ScienceDirect \\ A systematic literature review. $\quad$ C., Digby, R., Hay, P., \& Howe, A.
}

Prosedur penulisan literature review ini terdiri atas beberapa langkah antara lain :

1. Penentuan topik penelitian

Fokus pada satu topik penelitian yang jelas, topik review yang baik adalah dalam bentuk pertanyaan penelitian yang terdiri dari $5 \mathrm{~W}+1 \mathrm{H}$. Misalnya, (Why) Mengapa terjadi penurunan jumlah peserta didik baru secara drastis sejak pandemi Covid-19 terjadi? (What) Apakah solusi terbaik dalam mengatasi permasalahan tersebut? Dan seterusnya (Marzali, 2016). Selain prosedur di atas terdapat teknik dalam menentukan topik yang akan diteliti bisa dilakukan berdasarkan peta literatur dari T. Janovec dalam (John. W. Creswell, 2009).

2. Menyusun rancangan strategi penelitian

Setelah ditentukan topik penelitian maka langkah selanjutnya ada merumuskan strategi penelitian, seperti berapa banyak literatur yang akan dijadikan sumber rujukan. Berapa perpustakaan atau database yang ingin dikunjungi. Serta menentukan dateline penyelesaian penelitian.

3. Menelusuri beberapa penelitian terkait

Beberapa penelitian sebelumnya pasti sudah pernah dilakukan meskipun ada banyak perbedaan atau bahkan kekurangan dari penelitian sebelumnya. Untuk memperoleh data tersebut bisa dilakukan dengan bantuan internet agar mempersingkat waktu misalnya dengan menelusuri perpustakaan online atau media online yang menyediakan beberapa penelitian terkait.

Begitu banyak informasi yang diperoleh dari sana sehingga penulis harus pandai menyusun informasi tersebut secara efektif dan efisien.

4. Menulis kajian literature

Mulai mengerjakan penelitian sesuai dengan prosedur sehingga mempermudah penyelesaian dengan hasil yang baik (Gregory L. Wiltfang, 2017).

\title{
HASIL DAN PEMBAHASAN PENELITIAN
}

\section{Kemampuan Berfikir Kritis}

Kemampuan berfikir kritis sebagai keterampilan yang harus dikuasai siswa dalam menghadapi berbagai tuntutan di abad ke 21. Melalui kemampuan tersebut diharapkan siswa dapat memperoleh kesuksesan di segala aspek kehidupannya (Battele for kids, 2019), sebab berpikir kritis merupakan landasan utama menjadi manusia cerdas, karena mereka berhasil menyelesaikan permasalahan yang dihadapi melalui proses panjang hingga ditemukan solusi yang tepat atas permasalahannya. Berdasarkan pengalaman tersebut menjadikan siswa mampu menangani persoalan serupa atau bahkan persoalan yang lebih sulit di masa selanjutnya (Nuraini \& Suparman, 2018). Selain itu, siswa yang dibekali kemampuan berfikir secara kritis akan bersikap lebih teliti dalam menyikapi pendapat orang lain untuk mengetahui kebenaran sesungguhnya (Hidayat et al., 2016) melalui kemampuannya dalam mengolah informasi (Dwyer et al., 2015) apabila ditemukan keterangan atau informasi yang belum pasti kebenarannya hendaknya tidak dipercaya begitu saja namun perlu untuk mencari kebenaran yang sesungguhnya (Purwanto et al., 2012).

Berfikir kritis sebagai aktivitas kognitif dalam hal penyampaian gagasan melalui proses berfikir secara rasional (Arslan et al., 2014) yang tersampaikan baik secara langsung atau melalui tulisan (Agnah et al., 2018). Berpikir kritis sebagai dasar individu mencari solusi atas permasalahan yang dihadapi secara evaluatif, bahkan setiap permasalahan yang ada akan memberikan pengalaman tersendiri bagi siswa (Insyasiska et al., 2015). Pada era sekarang, nampaknya siswa tidak cukup hanya faham secara teori dalam proses pembelajaran, tetapi mereka juga harus melibatkan proses berfikir kritisnya dalam segala hal, baik ketika di kelas maupun 
dalam bersosialisasi dimasyarakat (Ahman \& Budiwati, 2018). Berfikir kritis memberikan manfaat terhadap siswa khususnya di abad 21 ini. Keadaan tersebut sangat jelas disampaikan melalui sebuah kerangka kerja pembelajaran yang inovatif abad 21 (Battele for kids, 2019).

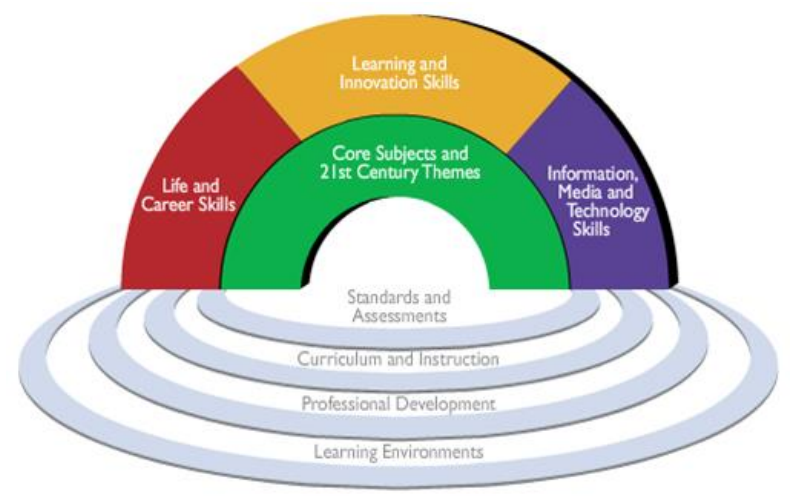

Gambar 1. Kerangka Kerja Pembelajaran Abad 21

Jika diperhatikan gambar di atas akan diperoleh pengertian bahwa aspek pengetahuan saja ternyata tidak cukup dalam memenuhi kebutuhan pendidikan dan tuntutan zaman yang juga senada dengan pendapat sebelumnya, berikut adalah daftar keterampilan yang perlu ditanamkan kepada siswa antara lain :

1. Pendidikan serta keahlian yang inovatif diantaranya berpikir kritis serta pemecahan permasalahan, kreativitas serta inovasi, komunikasi, serta kerja sama.

2. Keahlian hidup yang berkaitan dengan karir tertentu.

3. Penguasaan terhadap teknologi.

Dari sekian keterampilan-keterampilan yang dijabarkan di atas, terdapat keterampilan berfikir kritis sebagai keterampilan yang harus dikuasai siswa di era sekarang.

Kemampuan berpikir kritis akan membiasakan siswa lebih selektif terhadap informasi yang diterima. Sebagai fasilitator, guru diharapkan mampu mengemas pembelajaran sehingga siswa dapat menggali kemampuan berfikir kritis mereka dengan baik, suasana pembelajaran dapat dikemas semenarik dan efektif mungkin dalam menyampaikan materi. Atau bisa juga ditawarkan beberapa kegiatan yang dapat memacu kemampuan berfikir kritis dan termuat dalam rencana pembelajaran melalui model pembelajaran tertentu (Darmadi, 2019).

Selain model pembelajaran yang perlu diperhatikan, suasana belajar juga perlu diciptakan senyaman mungkin, guru menjalankan kewajibannya sebagai fasilitator dan motivator dengan baik, dan siswa tidak hanya duduk diam menerima informasi yang diperoleh namun perlu dilakukan klarifikasi atas informasi tersebut dengan aktif bertanya atau diskusi (Paringin et al., 2016). Lingkungan di sekolah memberikan peran signifikan dalam menciptakan kondisi belajar yang mengarahkan siswa menjadi pribadi kreatif yang di dalamnya termasuk memiliki kemampuan berfikir kritis (Davies et al., 2013). Pendekatan pembelajaran yang berbasis permasalahan dianggap lebih efektif dalam merangsang siswa agar berfikir secara kritis (Fachrurazi, 2011) pendekatan tersebut dapat diaplikasikan melalui model pembelajaran Guided Discovery (Purwanto et al., 2012). Discovery learning adalah model pembelajaran yang mengutamakan kemandirian siswa membangun berbagai informasi yang mereka terima melalui sebuah percobaan (trial), berdasarkan percobaan tersebut diperoleh sebuah prinsip (Boyer et al., 1999). Beberapa bukti penelitian juga menunjukkan hasil bahwa model pembelajaran guided discovery learning lebih efektif dalam meningkatkan berpikir kritis siswa jika dibandingkan dengan metode konvensional (Ahman \& Budiwati, 2018).

\section{Aspek-Aspek Berfikir Kritis}

Meskipun keterampilan berfikir kritis ini melekat pada setiap individu sejak lahir, namun tetap perlu 
2425 Model Pembelajaran Guided Discovery Learning, Apakah Efektif dalam Meningkatkan Kemampuan Berfikir Kritis Siswa? - Amanda Pasca Rini, I'in Khalimatus Sa'diyah, Abdul Muhid

DOI: https://doi.org/10.31004/edukatif.v3i5.641

dilatihkan melalui proses pembelajaran. Aspek berfikir kritis terdiri dari :

1. Memberikan klarifikasi dasar (elementary clasification) diantaranya : pemusatan pertanyaan, mengajukan dan mencatat pertanyaan yang memerlukan klarifikasi atau kesulitan.

2. Membangun kemampuan esensial (basic support), diantaranya : memikirkan tentang keterpercayaan sumber dan menyebutkan fakta secara objektif.

3. Penarikan kesimpulan (inference), diantaranya menyusun dan mempertimbangkan secara deduksi dan induksi serta menyusun hasil dan mempertimbangkannya.

4. Memberikan klarifikasi lebih lanjut (advance clarification), diantaranya : mengidentifikasi istilah dan mempertimbangkan definisi, mengidentifikasi asumsi.

5. Menetapkan teknik dan strategi (strategies and tactics), termasuk: memutuskan suatu kegiatan dan berinteraksi dengan orang lain.

6. Mengatur strategi dan taktik (strategies and tactics), seperti : menentukan suatu tindakan dan berinteraksi dengan orang lain (Reeder, 2011).

\section{Model Pembelajaran Guided Discovery Learning}

Discovery merupakan model pembelajaran yang dibuat dengan mengacu pada perspektif kontuktivisme. Model pembelajaran kontruktivisme akan melatih siswa terlibat aktif serta mengakomodasi kemampuan berpikir kritis mereka dalam proses belajar (Haris et al., 2015), pendidik memberikan fasilitas yang memudahkan siswa untuk membuat penemuan baru, dengan menerapkan pemikiran-pemikiran tertentu, dan menggunakan sistem yang terarah (Trianto, 2014), sebagai pusat perhatian (Wahyuni, 2021), siswa juga dihimbau untuk mengajukan pertanyaan-pertanyaan jika ditemui suatu kendala (Ariyani et al., 2017). Metode guided discovery learning mengutamakan keaktifan siswa dalam mengolah informasi melalui bimbingan dari guru dan kerja sama sesama siswa (Ahman \& Budiwati, 2018), misalnya dengan guru dapat menyampaikan topik secara umum terlebih dahulu, kemudian membimbing siswa untuk memahami topik secara utuh (Eggen, P \& Kauchak, D. (2012). Selain mampu meningkatkan kemampuan berfikir kritis, model ini juga dapat meningkatkan hasil belajar dan kepercayaan diri siswa (Imawan, 2015). Ada empat perspektif utama dalam model ini, yaitu (1) adanya struktur pembelajaran, (2) siswa berkewajiban dalam menemukan materi yang seharusnya diperoleh (3) adanya arahan dalam pembelajaran (4) proses menemukan dan menangani masalah (Spencer \& Jordan, 1999).

\section{Tahapan Guided Discovery Learning}

Terdapat beberapa tahapan dalam model pembelajaran guided discovery learning antara lain :

\section{Orientation}

Pendidik memberikan prolog untuk mengumpulkan ide-ide siswa dengan cara membaca sumber-sumber tulisan, persepsi tertentu, sehingga memunculkan masalah. Guru membimbing siswa untuk mengajukan pertanyaan dan masalah. Pertanyaan-pertanyaan yang diajukan oleh siswa menjadi definisi dari masalah yang akan dibahas.

2. Hypothesis Generation

Pendidik menawarkan kesempatan pada siswa untuk mengembangkan hipotesis. Hipotesis disusun berdasarkan informasi awal siswa untuk memutuskan tanggapan sementara terhadap masalah yang telah ditentukan sebelumnya.

3. Fase Conclusion

Tahapan penyimpulan hasil eksperimen. Hipotesis menjadi salah satu jawaban permasalahan atau harus dipertimbangkan kembali oleh hasil eksplorasi tersebut.

4. Fase Regulation

Fase ini berkaitan dengan hasil melalui pengungkapan ukuran pembelajaran dan penilaian akhir yang telah 
2426 Model Pembelajaran Guided Discovery Learning, Apakah Efektif dalam Meningkatkan Kemampuan Berfikir Kritis Siswa? - Amanda Pasca Rini, I'in Khalimatus Sa'diyah, Abdul Muhid

DOI: https://doi.org/10.31004/edukatif.v3i5.641

dibuat. Latihan penilaian digunakan untuk memeriksa pengaturan yang telah dibuat siswa, sehingga kesepakatan siswa sesuai dengan ide yang tepat dan dapat menyelesaikan tujuan pembelajaran (Veermans, 2002).

Sedangkan menurut (Eggen \& Kauchak, 2012) model guided discovery learning terdiri dari beberapa tahapan antara lain :

1. Pendahuluan, pendidik berusaha mendorong siswa untuk agar focus pada pembelajaran.

2. Guru memberikan model dan contoh ide untuk mendorong siswa agar lebih dinamis dalam mengajukan pertanyaan.

3. Guru membuat pertanyaan yang lebih eksplisit untuk mengontrol siswa agar mendapatkan ide.

4. Guru membantu siswa untuk lebih memahami ide-ide dan menerapkannya.

\section{Kelebihan Guided Discovery Learning}

Model pembelajaran yang dipilih dalam ukuran pembelajaran harus disesuaikan dengan kebutuhan dan tujuan pembelajaran dengan alasan bahwa setiap model pembelajaran memiliki kelebihan dan kekurangannya sendiri, misalnya model guided discovery learning yang memiliki beberapa keunggulan, antara lain: :

1. Membantu siswa meningkatkan kemampuan kognitif.

2. Informasi atau data yang diperoleh melalui model guided discovery learning dapat dapat memperkuat memori.

3. Dapat meningkatkan kapasitas siswa untuk menangani masalah.

4. Membantu memperkuat ide diri siswa, karena mereka mendapat kesempatan untuk bekerja sama dengan yang lain.

5. Mendesak siswa untuk terlibat secara aktif dan efektif dengan pembelajaran.

6. Mendorong siswa berpikir secara alami dan merencanakan hupotesis mereka sendiri.

7. Melatih siswa untuk beradaptasi dengan bebas.

Senada dengan pendapat di atas, (Eggen \& Kauchak, 2012) berpendapat terkait kelebihan model pembelajaran guided discovery learning bahwa apabila model ini dipraktikkan dengan benar, akan menghasilkan pemahaman konsep secara mendalam pada siswa dan menghasilkan penyimpanan informasi jangka panjang yang baik, serta mendorong siswa berpikir kritis. Namun terdapat pula kelemahan model pembelajaran ini yaitu cenderung menyita lebih banyak waktu dan apabila siswa tidak mendengarkan secara cermat apa yang disampaikan guru atau sesiwa lain, mereka kerap memiliki konsepsi yang kurang tepat tentang topic yang sedang mereka pelajari.

Sesuai dengan gagasan sebelumnya, (Eggen \& Kauchak, 2012) berpendapat tentang kelebihan model guided discovery learning bahwa jika model ini dilatih secara efektif, akan menghasilkan pemahaman ide-ide dari atas ke bawah pada siswa dan menghasilkan ingatan jangka panjang yang baik. penimbunan data, dan mendorong siswa untuk berpikir secara mendasar. Meskipun demikian, ada juga kekurangan dalam model pembelajaran ini, yang pada umumnya akan memakan waktu lebih lama dan jika siswa tidak mendengarkan dengan seksama apa yang dikatakan guru atau siswa lain, mereka sering memiliki konsep yang salah dari mata pelajaran yang mereka pelajari. Jika beberapa penelitian sebelumnya menjelaskan implementasi metode guided discovery learning pada beberapa pelajaran tertentu saja namun dengan mempelajari konsep guided discovery learning lebih mendalam diharapkan model tersebut dapat diaplikasikan pada semua pelajaran mengingat pengaruhnya yang yang sangat luas terhadap kehidupan siswa, bukan hanya secara akademik bahkan secara social. Karena siswa terlatih berfikir secara kritis atas apa yang ditemuinya. Baik tentang masalah yang dihadapi di sekolah maupun bekal untuk kehidupan di masyarakat. 
2427 Model Pembelajaran Guided Discovery Learning, Apakah Efektif dalam Meningkatkan Kemampuan Berfikir Kritis Siswa? - Amanda Pasca Rini, I'in Khalimatus Sa'diyah, Abdul Muhid

DOI: https://doi.org/10.31004/edukatif.v3i5.641

\section{KESIMPULAN}

Kemampuan berfikir kritis siswa dapat ditingkatkan melalui model pembelajaran yang mendukung, dimana siswa terlibat secara aktif dalam proses belajar mereka. Salah satu model pembelajaran yang dapat meningkatkan kemampuan berfikir kritis siswa adalah model pembelajaran guided discovery learning. Model pembelajaran guided discovery learning menjadikan kondisi di dalam kelas lebih interaktif, karena siswa dituntut untuk aktif menemukan jawaban atas pertanyaan-pertanyaan yang ditemui melalui bimbingan guru agar diperoleh konsep pengetahuan yang benar.

\section{DAFTAR PUSTAKA}

Agnah, S. M., Rusdi, \& Herlanti, Y. (2018). Pengaruh Metode Peta Argumen Dan Efikasi Diri Terhadap Kemampuan Berpikir Kritis. Edusains, 10(2), 217-225.

Ahman, E., \& Budiwati, N. (2018). Metode Guided Discovery Learning Terhadap Tingkat Berpikir Kritis Siswa Dilihat Dari Motivasi Belajar. Indonesian Journal Of Economics Education, 1(1), 1-8. Https://Doi.Org/10.17509/Jurnal

Ariyani, R. D., Indrawati, \& Mahardika, I. K. (2017). Model Pembelajaran Guided Discovery ( Gd ) Disertai Media Audiovisual Dalam Pembelajaran Ipa ( Fisika ) Di Smp. Jurnal Pendidikan Fisika, 6(4), 397-403.

Arslan, R., Gulveren, H., \& Aydin, E. (2014). A Research On Critical Thinking Tendencies And Factors That Affect Critical Thinking Of Higher Education Students. International Journal Of Business And Management, 9(5), 43-59. Https://Doi.Org/10.5539/Ijbm.V9n5p43

Battele For Kids. (2019). Framework For 21st Century Learning Definitions. Partnership For 21st Century Learning, 9. Http://Static.Battelleforkids.Org/Documents/P21/P21_Framework_Definitionsbfk.Pdf

Boyer, J. P., Théorie, J. P. B., Calcul, E. T., Index, D. E. S., \& Annales, D. E. S. (1999). Cognitive Tools For Discovery Learning. 7(3), 193-242.

Collard, P., \& Looney, J. (2014). Nurturing Creativity In Education. European Journal Of Education, 49(3), 348-364. Https://Doi.Org/10.1111/Ejed.12090

Darmadi, H. (2019). Pengantar Pendidikan Era Globalisasi. Animage.

Davies, D., Jindal-Snape, D., Collier, C., Digby, R., Hay, P., \& Howe, A. (2013). Creative Learning Environments In Education-A Systematic Literature Review. Thinking Skills And Creativity, 8(1), 8091. Https://Doi.Org/10.1016/J.Tsc.2012.07.004

Diah Rusmala Dewi. (2019). Pengembangan Kurikulum Di Indonesia Dalam Menghadapi Tuntutan Abad Ke21. As-Salam: Jurnal Studi Hukum Islam \& Pendidikan, 8(1), 1-22. Https://Doi.Org/10.51226/Assalam.V8i1.123

Drake, S., \& Reid, J. (2018). Integrated Curriculum As An Effective Way To Teach 21st Century Capabilities. Asia Pacific Journal Of Educational Research, 1(1), 31-50. Https://Doi.Org/10.30777/Apjer.2018.1.1.03

Dwyer, C. P., Hogan, M. J., \& Stewart, I. (2015). The Effects Of Argument Mapping-Infused Critical Thinking Instruction On Reflective Judgement Performance. Thinking Skills And Creativity, 16, 11-26. Https://Doi.Org/10.1016/J.Tsc.2014.12.002

Eggen, P., \& Kauchak, D. (2012). Strategi Dan Model Pembelajaran. Indeks.

Fachrurazi. (2011). Penerapan Pembelajaran Berbasis Masalah Untuk Meningkatkan Kemampuan Berpikir Kritis Dan Komunikasi Matematis Siswa Sekolah Dasar. Jurnal Penelitian Pendidikan Upi, Edisi Khus(1), 76-89. Http://Jurnal.Upi.Edu/Penelitian-Pendidikan/View/637/

Gregory L. Wiltfang. (2017). Review Reviewed Work ( S ): Qualitative Research Methods For The Social Sciences By Bruce L. Berg Review By : Gregory L . Wiltfang Source : Teaching Sociology, Vol . 18 , No . 4 ( Oct ., 1990 ), Pp . 563-565 Published By: American Sociological Associat. Teaching Sociology, 
2428 Model Pembelajaran Guided Discovery Learning, Apakah Efektif dalam Meningkatkan Kemampuan Berfikir Kritis Siswa? - Amanda Pasca Rini, I'in Khalimatus Sa'diyah, Abdul Muhid

DOI: https://doi.org/10.31004/edukatif.v3i5.641

$18(4), 563-565$.

Haris, F., Rinanto, Y., \& Fatmawati, U. (2015). Pengaruh Model Guided Discovery Learning Terhadap Kemampuan Berpikir Kritis Siswa Kelas X Sma Negeri Karangpandan Tahun Pelajaran 2013/2014. Jurnal Pendidikan Biologi, 7, 114-122.

Hidayat, A., Rahayu, S., \& Rahmawati, I. (2016). Analisis Keterampilan Berpikir Kritis Siswa Smp Pada Materi Gaya Dan Penerapannya. In Pros. Semnas Pend. Ipa Pascasarjana Um (Vol. 1, Pp. 1112-1119).

Imawan, O. R. (2015). Perbandingan Antara Keefektifan Model Guided Discovery Learning Dan ProjectBased Learning Pada Matakuliah Geometri. Pythagoras: Jurnal Pendidikan Matematika, 10(2), 179. Https://Doi.Org/10.21831/Pg.V10i2.9156

Insyasiska, D., Zubaidah, S., \& Susilo, H. (2015). Pengaruh Project Based Learning Terhadap Motivasi Belajar, Kreativitas, Kemampuan Berpikir Kritis, Dan Kemampuan Kognitif Siswa Pada Pembelajaran Biologi. Jurnal Pendidikan Biologi, 7(1), 9-21. Https://Doi.Org/10.17977/Um052v7i1p9-21

John. W. Creswell. (2009). Research Design. Qualitative, Quantitative, And Mixed Methods Approaches. In Sage Publication. Https://Doi.Org/10.1080/14675980902922143

Marzali, A. (2016). Menulis Kajian Literatur. Jurnal Etnosia, 1(2), 27-36.

Mayer, R. E. (2004). Should There Be A Three-Strikes Rule Against Pure Discovery Learning? The Case For Guided Methods Of Instruction. American Psychologist, 59(1), 14-19. Https://Doi.Org/10.1037/0003066x.59.1.14

Mukarromah, A. (2018). Analisis Kemampuan Berpikir Kritis Pada Model Discovery Learning Berdasarkan Pembelajaran Tematik. Indonesian Journal of Primary Education, 2(1), 38 Https://Doi.Org/10.17509/Ijpe.V2i1.11844

Nuraini, R., \& Suparman, S. (2018). Deskripsi Kemampuan Berpikir Kritis Dan Kreatif Siswa Melalui Penerapan Pendekatan Saintifik. Prosiding Seminar Nasional Pendidikan Matematika ..., 702-707.

Paringin, S., Mata, P., \& Ipa, P. (2016). Analisis Kemampuan Berpikir Kritis Siswa Kelas Ix. Jurnal Pendidikan, 2006, 179-186.

Partnership For 21st Century - A Network Of Battelle For Kids [P21]. (2019). Framework For 21st Century Learning. Partnership For 21st Century Learning Http://Static.Battelleforkids.Org/Documen\%0ats/P21/P21_Framework_Brief.Pdf

Purwanto, C. E., Nughoro, S. E., \& Wiyanto. (2012). Penerapan Model Pembelajaran Guided Discovery Pada Materi Pemantulan Cahaya Untuk Meningkatkan Berpikir Kritis. Unnes Physics Education Journal, 1(1). Https://Doi.Org/10.15294/Upej.V1i1.768

Putriani, J. D. (2021). Penerapan Pendidikan Indonesia Di Era Revolusi Industri 4 . 0. Edukatif: Jurnal Ilmu Pendidikan, 3(3), 831-838.

Reeder, H. (2011). The Nature Of Critical Thinking. Informal Logic, 6(2), 1-8. Https://Doi.Org/10.22329/Il.V6i2.2729

Saleh, S. E. (2019). European Journal Of Foreign Language Teaching Critical Thinking As A 21 St Century Skill: Conceptions, Implementation And Challenges In The Efl Classroom. European Journal Of Foreign Language Teaching, O(0), 1-16. Https://Doi.Org/10.5281/Zenodo.2542838

Salmi, S. (2019). Penerapan Model Pembelajaran Discovery Learning Dalam Meningkatkan Hasil Belajar Ekonomi Peserta Didik Kelas Xii Ips.2 Sma Negeri 13 Palembang. Jurnal Profit Kajian Pendidikan Ekonomi Dan Ilmu Ekonomi, 6(1), 1-16. Https://Doi.Org/10.36706/Jp.V6i1.7865

Santrock J.W. (2011). Educational Psychology (5th Ed). Mc. Graw-Hill.

Spencer, J. A., \& Jordan, R. K. (1999). Learner Centred Approaches In Medical Education. British Medical Journal, 318(7193), 1280-1283. Https://Doi.Org/10.1136/Bmj.318.7193.1280 
2429 Model Pembelajaran Guided Discovery Learning, Apakah Efektif dalam Meningkatkan Kemampuan Berfikir Kritis Siswa? - Amanda Pasca Rini, I'in Khalimatus Sa'diyah, Abdul Muhid

DOI: https://doi.org/10.31004/edukatif.v3i5.641

Trianto. (2014). Mendesain Model Pembelajaran Inovatif-Progresif. Kencana Prenada Media Group.

Veermans, K. (2002). Intelligent Support For Discovery Learning. In Educational Research. Http://Doc.Utwente.Nl/38699/1/T000001b.Pdf

Wahyuni, Z. A. (2021). Praktikalitas E-Modul Kimia Unsur Berbasis Guided Discovery Untuk Siswa Sekolah Menengah Atas. Edukatif: Jurnal Ilmu Pendidikan, 3(3), 680-688. 